\title{
The maze behavior of hippocampectomized rats under massed and distributed trials'
}

\author{
MILLARD C. MADSEN AND DANIEL P. KIMBLE
}

UNIIERSITY OF OREGON

\begin{abstract}
Twenty-four rats with bilateral hippocampal lesions and 24 intact controls were trained for 12 trials in a Lashley III maze. Half of each group had a $10 \mathrm{sec}$. intertrial interval and the other half a $10 \mathrm{~min}$. intertrial interval. Results indicated a highly significant lesion effect and a tendency for the hippocampectomized Ss to perform better under the more distributed condition.
\end{abstract}

\section{Problem}

The reports of recent term memory deficits in humans with hippocampal damage (Penfield \& Milner, 1958; Scoville, 1954; Scoville \& Milner, 1957) have focused attention on the function of temporal lobe structures in memory storage. The implication of these reports is that performance of hippocampectomized Ss will deteriorate as the interval between stimulus presentation and retention test is increased-or as the intertrial interval between successive acquisition trials on the same task is increased. The short term memory deficit hypothesis is particularly interesting in the context of the latter experimental paradigm as the predicted outcome is opposite to the evidence on facilitation of learning with distributed practice in normal Ss. Kimble \& Pribram (1963) varied intertrial interval on visual discriminations and found that both hippocampectomized and control lesioned monkeys made fewer errors under the more distributed conditions, a finding consistent with the results of Orbach et al (1960).

The failure to validate the short term memory deficit hypothesis by varying intertrial interval is not, however, inconsistent with a theory of memory consolidation. McGaugh et al (1962) found that descendents of the Tryon maze-bright and maze-dull strains differed in Lashley III maze acquisition only when training trials were massed (30 sec. intertrial interval) while the maze-dulls performed as well as the maze-brights under three longer intertrial intervals. Madsen (1963) found a similar interaction between intertrial interval and capacity in paired associate learning by mentally retarded and normal children. The groups differed much more when successive trials were administered with a $5 \mathrm{sec}$. intertrial interval than with a $60 \mathrm{sec}$. intertrial interval. These results were interpreted as indicating a slower rate of posttrial consolidation for the mazedull rats and the mentally retarded children. When sufficient time for optimum consolidation of the neurophysiological processes responsible for memory storage is allowed individual differences tend to decrease. A brain lesion may be considered to have the effect of altering capacity for storing information by rendering the neurophysiological storage mechanism less efficient. A relatively longer intertrial interval would allow for increased consolidation in the deficient Ss, while optimal storage is achieved in a shorter period in intact Ss. This molar hypothesis predicts an interaction between capacity and intertrial interval, but in the opposite direction of the interaction indicated by the short term memory deficit hypothesis.

\section{Method}

Forty-eight naive Sprague-Dawley rats (24 males and 24 females) 80-100 days old were used as Ss. Twentyfour Ss (12 males and 12 females) received bilateral hippocampal lesions and the other 24 served as normal controls. The hippocampus was aspirated bilaterally in one stage following surgical procedures described previously (Kimble, 1963). An examination of the sectioned brains revealed that the hippocampus was severed bilaterally in all operated Ss, the dorsolateral aspect being most affected. The lesions were similar to those reported previously (Kimble, 1963)。

The apparatus consisted of a 48 in pretraining alley and a four unit, 8 cul Lashley III alley maze. The maze units were 6 in wide, 6 in high, and 48 in long. Both the pretraining alley and maze were painted grey and covered with hardware cloth. White lines on the floor 2 in from both sides of the entrance to each alley served as error lines.

The hippocampectomized Ss received a 10 day postoperative recovery period prior to pretraining. On day 11 all Ss were deprived of water for $24 \mathrm{hr}$. and then received five massed pretraining trials/day for five consecutive days for a $20 \mathrm{sec}$. water reward. Following the fifth pretraining trial on each day Ss were allowed access to water in the goal box for $5 \mathrm{~min}$. Ss received no water in the home cage from the beginning of pretraining to the end of the experiment. On day $11 \mathrm{Ss}$ received 12 trials in the Lashley III maze for a $10 \mathrm{sec}$. water reward. Twelve operated Ss and 12 controls were run under massed conditions with only the $10 \mathrm{sec}$. drinking time between trials. The other hippocampectomized Ss and 12 controls were placed in their home cages for $10 \mathrm{~min}$. between trials. Ss received $5 \mathrm{~min}$. of drinking time in the goal box following trial 12. A single trial retention test was given $24 \mathrm{hr}$. later. An error was recorded when S's foot crossed the error line. Errors were not recorded for successive crossings of the same cul entrance until a different error line had been crossed. 


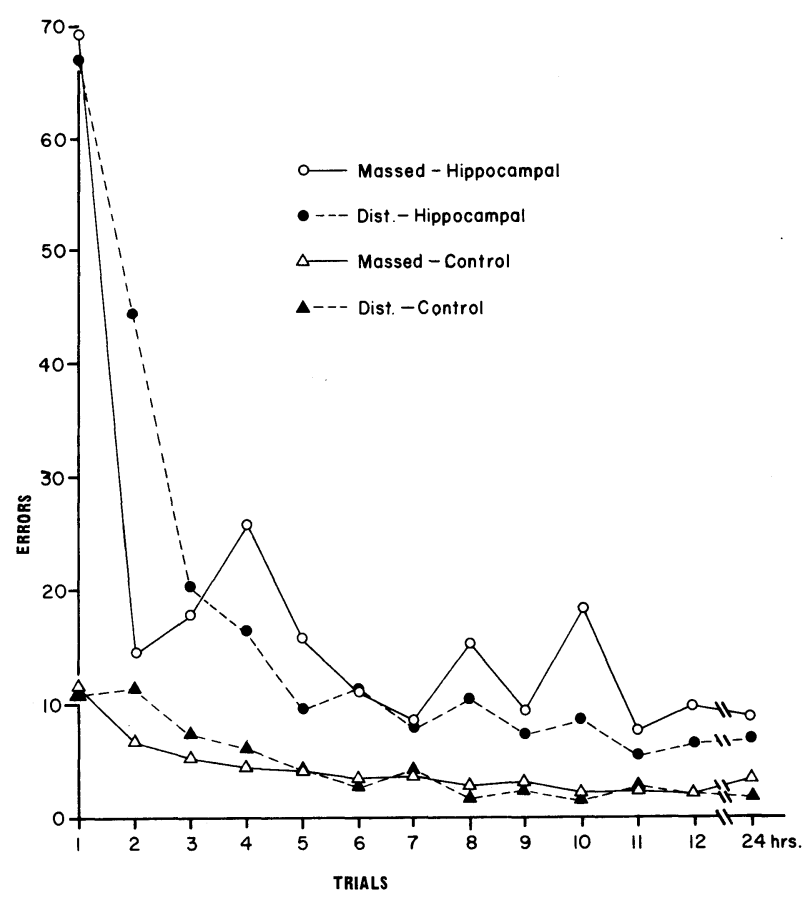

Fig. 1. Mean errors trial in Lashley III maze for hippocampectomized and unoperated control rats under massed and distributed practice.

\section{Hesults}

An analysis of variance for total errors from trial 2 through 12 (lesion $\mathrm{x}$ condition of practice $\mathrm{x}$ sex) indicated a highly significant lesion effect $(F=107.3$, df $1 / 40, p<.001$ ) but no significant condition of practice or sex effects. Mean total errors were as follows: hippocampal-massed, 153.9; hippocampal-distributed, 147.5; control-massed, 41.8; control-distributed, 46.2.

Figure 1 indicates that the hippocampectomized Ss trained under the distributed condition made fewer errors on trials 4-12. The large difference between groups on trial 2 in the reverse direction, however, greatly diminished the mean difference between the massed and distributed groups for total errors. An analysis of variance of trial 12 errors was performed to investigate the effects of allowing the temporal variable the maximum number of trials to operate. This analysis indicated a significant lesion effect $(\mathrm{F}=22.56$, df $1 / 40, \mathrm{p}<.001)$ and no significant effects due to condition of practice or sex. Comparison of means (hippocampal-massed, 9.7; hippocampal-distributed, 6.3; control-massed, 2.2; control-distributed, 2.2) by the Newman Keuls technique (Winer, 1962) indicated significant differences $(p<.01)$ between massed-hippocampals and massed-controls and between distributedhippocampals and distributed-controls $(p<.05)$. The difference between hippocampal-massed and hippocampal-distributed fell just short of the .05 level (twotailed). A one-tailed test was significant at .03. An analysis of variance of difference scores between errors on trial 12 and errors on the $24 \mathrm{hr}$. retention test indicated that the $24 \mathrm{hr}$. interval did not significantly affect the relative amount retained by the different groups.

\section{Discussion}

The results clearly confirm previous reports that animals with hippocampal lesions are deficient in the acquisition of a complex maze (Kimble, 1963; Kaada et al, 1961). The intertrial interval and intertrial interval $\mathrm{x}$ lesion interaction effects, while not highly significant statistically, are in the direction predicted by an extension of the consolidation hypothesis and in the opposite direction of that predicted by the short term memory deficit hypothesis.

\section{References}

Jarrard, J. E., \& Lewis, T. C. Effects of hippocampal ablation and intertrial interval on complex maze acquisition and extinction Paper presented at the Midwestern Psychological Association, St Louis, May, 1964.

Kaada, B. R., Rasmussen, E. W., \& Kviem, O. Effects of hippocampal lesions on maze learning and retention in rats. Exp. Neurol., 1961, 3, 333-355.

Kimble, D. P. The effects of bilateral hippocampal lesions in rats J. comp. physiol. Psychol., 1963, 56, 273-283

Kimble, D. P., \& Pribram, K. H. Hippocampectomy and behavior sequences. Science, 1963, 139, 824-825.

Madsen, M. C. Distribution of practice and level of intelligence. Psychol. Rep..1963, 13, 39-42.

McGaugh, J. L., Jennings, R. N., \& Thomson, C. w. Effect of distribution of practice on the maze learning of descendants of the Tryon maze bright and maze dull strains. Psychol. Rep., 1962, $10,147-150$

Orbach, J., Milner, Brenda, \& Rasmussen, T. Learning and retention in monkeys after amygdala-hippocampus resection. Arch. Neurol., 1960, 3, 230.

Penfield, W., \& Milner, Brenda. Memory deficit produced by bilateral lesions in the hippocampal zone. AMA Arch. Neurol. Psychiat., 1958, 79, 475-479.

Scoville, W. B. The limbic lobe in man. J. Neurosurg., 1954, 11, 64-66.

Scoville, W. B., \& Milner, Brenda. Loss of recent memory after bilateral hippocampal lesions. J. Neurol. Neurosurg. Psychiat., 1957, 20, 11-21.

winer, B. J. Statistical principles in experimental design. New York: McGraw-Hill, 1962.

\section{Note}

1. This investigation was supported in part by a Public Health Service Research Grant, MH 08545-02 from the National Institute of Mental Health, D. P. Kimble, principal investigator, and a USPHS predoctoral fellowship awarded to M. Madsen. All lesions were performed by D. P. Kimble, During the preparation of this manuscript, the similar unpublished findings of Jarrard and Lewis came to our attention. 